\title{
The Electrical Activity of the Heart during Ventricular Repolarization and Types of the Remodeling of the Athlete`s Heart
}

\author{
Natalya I. Panteleeva, $\mathrm{PhD}^{1 *}$; Elena V. Zamenina ${ }^{1}$; \\ Irina. M. Roshchevskaya, $\mathrm{PhD}, \mathrm{ScD}^{2,3}$; Irina N. Kaneva ${ }^{4}$ \\ ${ }^{1}$ Department of Comparative Cardiology, Komi Science Centre UB RAS, Syktyvkar, the Russian Federation \\ ${ }^{2}$ Pitirim Sorokin Syktyvkar State University, Syktyvkar, the Russian Federation \\ ${ }^{3}$ Research Zakusov institute of pharmacology, Moscow, the Russian Federation \\ ${ }^{4}$ SI KR Cardiology Clinic Syktyvkar, the Russian Federation
}

\begin{abstract}
The aim of this work was to investigate the electrical activity of the athletes' hearts with different types of the left ventricular remodeling, as well as a control group of untrained people, by the body surface potential mapping before and immediately after exercising. The study of the heart's electric field in athletes of the same sex, age and sport qualification, but different sport disciplines, showed that the reaction of the heart to physical activity is reflected in different changes of the amplitudetemporal characteristics of the extremes on the body's surface in athletes with eccentric and concentric myocardial remodeling. (International Journal of Biomedicine. 2019;9(4):297-299.)
\end{abstract}

Key Words: ventricular repolarization $\bullet$ ventricular remodeling $\bullet$ electrical activity $\bullet$ body surface potential mapping

\section{Abbreviations}

ARD, aortic root diameter; BSPM, body surface potential mapping; HR, heart rate; LVEDD, left ventricular (LV) end-diastolic diameter; LVM, LV mass; LVMI, LV mass index; PWT, posterior wall thickness; LVRWT, LV relative wall thickness; LVEF, LV ejection fraction; SWT, septal wall thickness; VR, ventricular repolarization.

\section{Introduction}

The specificity of sports specialization ${ }^{(1)}$ defines the type of "sports heart" remodeling. . $^{(2,3)}$ In endurance athletes, an increase of myocardial preload leads to an increase in the size of the heart and ventricular cavities and an increase in the stroke volume, and forms the eccentric hypertrophy of the left ventricle. In strength athletes an increase of myocardial afterload leads to an increase in the mass of the LV myocardium without dilatation of the cavities, and forms the concentric myocardial hypertrophy. ${ }^{(3,4)}$ Structural and functional cardiac remodeling leads to electrophysiological remodeling. ${ }^{(5)}$ Using

*Corresponding author: Natalya I. Panteleeva, PhD. Department of Comparative Cardiology, Komi Science Centre UB RAS. Syktyvkar, the Russian Federation.E-mail: bdr13@mail.ru standard ECG on an athlete's heart during VR, the general particularities are: J-point elevation, ST segment elevation/ depression, tall and peaked T-wave, and isoelectric, biphasic or inverted T-waves. ${ }^{(6,7)}$ When an athlete performs physical exercise, these ECG features disappear, which confirms their functional, rather than structural, origin. ${ }^{(8)}$ BSPM method, known as a noninvasive, multichannel, synchronous recording of electrical potentials of the heart on the thoracic surface from multiple unipolar leads, is a more informative method for studying the functional state of the heart, which makes it possible to obtain more data on the electrical processes in the myocardium than with the standard electrocardiography. ${ }^{(9,10)}$

The aim of this work was to investigate the electrical activity of the athletes' hearts with different types of the LV remodeling, as well as a control group of untrained people, by the BSPM before and immediately after exercising. 


\section{Materials and Methods}

The 25 athletes were examined by the methods of echoand electrocardiography. All athletes were male with the sports qualifications of candidates for Master of Sports of Russia and Master of Sports of Russia. Three sporting disciplines predominantly made up the study group: swimming $(n=10$; age of $19.5 \pm 0.5$ years; weight of $76.0 \pm 9.5 \mathrm{~kg}$; height of $179 \pm 6$ $\mathrm{cm})$, weightlifting $(\mathrm{n}=8$; age of $19.5 \pm 1.5$ years; weight of $77.6 \pm 8.3 \mathrm{~kg}$; height of $174.3 \pm 6.0 \mathrm{~cm}$ ) and cross-country skiing $(\mathrm{n}=7$; age of $18.9 \pm 1.1$ years; weight of $76 \pm 4.0 \mathrm{~kg}$; height of $178.1 \pm 3.2 \mathrm{~cm})$. The control group comprised 9 healthy adult volunteers (age of 19,7 $\pm 0,8$ years; weight of $70,8 \pm 6,4 \mathrm{~kg}$; height of $176,9 \pm 4,9 \mathrm{~cm})$.

\section{Echocardiography}

Two-dimensional EchoCG was perfumed with the subjects resting in a left lateral decubitus position using LOGIC Pro (GE, USA) with a $5 \mathrm{MHz}$ transducer. The heart images obtained in $\mathrm{M}$ - and B- modes in the standard parasternal long-axis and four chambers positions, according to guidelines of the American Society of Echocardiography, ${ }^{(11)}$ were used to measure LVEDV, SWT, PWT, and ARD. The Devereux formula (1986) was used to calculate LVM (g). We calculated LVMI $\left(\mathrm{g} / \mathrm{m}^{2}\right)$ as the ratio of LVM to body surface area, LVRWT as the ratio of double PWT to LVEDV, and LVEF using the Teichholz method.

\section{Multichannel electrocardiography}

The heart's electrical activity in the young men was studied using multichannel ECG during VR. BSPM with 64 unipolar leads covering the thorax was performed; Standard lead II was used as the reference. ${ }^{(9)}$ The electrodes were located evenly on the ventral and dorsal surfaces of the torso with a $3-5 \mathrm{~cm}$ distance between them. The electrodes were attached to 8 flexible strips, each containing 8 electrodes. BSPM was recorded at rest and during the recovery period after submaximal physical exercise. Using a bicycle ergometer (KETTLER, Germany), subjects performed two workloads, each lasting 5 minutes. The first (moderate) workload corresponded to $1.5 \mathrm{~W} / \mathrm{kg}$ body weight. The second workload was submaximal and was calculated according HR at the fifth minute of the first workload. During the second workload, HR of the subjects reached $170 \mathrm{bpm}$. After each load, there was a 3-minute recovery period.

We analyzed the amplitude characteristics of the positive and negative extremes (the amplitude of the maximum and the minimum, respectively) and the time they reached the maximum amplitudes at the period of VR (the maximum time and the minimum time, respectively).

The study was conducted in accordance with ethical principles of the WMA Declaration of Helsinki (1964, ed. 2013) and approved by the KSC UB RAS Ethics Committee. Written informed consent was obtained from all participants.

Statistical analysis was performed using the statistical software SPSS version 22.0. The normality of distribution of continuous variables was tested by the Shapiro-Wilk test. Variables were presented as mean $+\mathrm{SD}$. For data with normal distribution, inter-group comparisons were performed using Student's t-test.
Differences of continuous variables departing from the normal distribution were tested by the Mann-Whitney U-test. A probability value of $P<0.05$ was considered statistically significant.

\section{Results}

According to recommendations ${ }^{(11)}$ as the result of an echocardiographic study, two types of LV remodeling were revealed in the subjects: eccentric (cross-country skiers and swimmers) and concentric (weightlifters).

Indicators of LVM, LVMI, and LVRWT were as follows: in skiers - 217.3 $\pm 31.6 \mathrm{~g}, 112.7 \pm 15.0 \mathrm{~g} / \mathrm{m}^{2}$, and $0.35 \pm 0.01$; in swimmers - $192.6 \pm 1.3 \mathrm{~g}, 100.0 \pm 9.8 \mathrm{~g} / \mathrm{m}^{2}$; and $0.37 \pm 0.02$; in weightlifters $-153.4 \pm 40.7 \mathrm{~g}, 87.4 \pm 19.3 \mathrm{~g} / \mathrm{m}^{2}$, and $0.33 \pm 0.01$, respectively.

In comparison with the untrained people, significant differences were revealed in the indicators of LVM and LVMI for skiers and swimmers, and in the indicator of LVRWT for weightlifters. A statistically significant difference was revealed between skiers and weightlifters in the indicators of LVM and LVMI.

The amplitude of positive extremum in weightlifters and untrained people increased during the recovery period (2, 3 min), in swimmers and skiers at the cessation of exercise (1 min recovery). The maximal increase in positive extremum was found in skiers.

The amplitude of negative extremum was increased (vs. baseline) in all subjects at the cessation of exercise, and decreased during 3 minutes of the recovery period until it reached the initial value (excluding untrained people).

In all subjects, the time required to reach the maximal values for positive and negative extremes decreased significantly in comparison with initial values after exercise. The maximal decrease was obtained in swimmers (by $44 \%$ for $\mathrm{t}_{\min }$ and $40 \%$ for $\mathrm{t}_{\max }$ ), and minimal in weightlifters (by $39 \%$ for $\mathrm{t}_{\text {min }}$ and $\mathrm{t}_{\text {max }}$ ) (Table 1 ).

According to anthropometric data, the compared groups were similar. Studies on humans and animals have shown that the chest size, fat tissue and size of the pectoral muscles have a slight effect on the heart's electrical activity on the body surface..$^{(9,12)}$ Therefore, the difference in the ratio of muscle, fat and bone tissue among athletes of different sports ${ }^{(13)}$ can be neglected, and the revealed differences in the BSPM characteristics are due to the influence of the type of myocardial remodeling. During physical workload, the indicators of HR and stroke volume increase rapidly; as a result, the strength of myocardial contraction increases, and these changes are much greater in athletes than in untrained people.

In comparison with weightlifters, the cross-country skiers and the swimmers have a larger heart size and volume of the left ventricle, but have less thickness of the interventricular septum and posterior wall of the left ventricle. Earlier, we showed that in cross-country skiers and weightlifters the duration of the ventricular depolarization period of the heart was the same, but the duration of the different phases of depolarization was different. These differences indicate a difference in the heart's electrical activity in athletes with eccentric and concentric types of myocardial remodeling. 
According to the BSPM results of this study, during the period of VR, the temporal characteristics of the extremes after exercise change maximally in endurance athletes (swimmers and skiers), and minimally in strength athletes (weightlifters). As a result of a static training in weightlifting, a ventricular pressure overload leads to a thickening of the heart wall, ${ }^{(15)}$ and the diameter of the myofibrils in the cardiomyocytes increases without an increase in their number. ${ }^{(16)}$ In dynamic training in cross-country skiing, overload of ventricles by volume leads to lengthening of cardiomyocytes. According to experimental data on animals with pathological hypertrophy of the left ventricular, the $t_{\max }$ extremes increase during VR. . $^{(17)}$ In our study, there were no differences in the indicators of the maximum time and the minimum time between athletes with eccentric and concentric myocardial remodeling at baseline, which confirms the physiological origin of wall thickening in weightlifters.

\section{Table 1.}

The amplitude-temporal characteristics of the extremes in subjects during rest and recovery period after submaximal workload

\begin{tabular}{|c|c|c|c|c|c|}
\hline \multirow{2}{*}{ 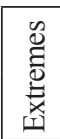 } & \multirow{2}{*}{ Subjects } & \multirow{2}{*}{ Baseline } & \multicolumn{3}{|c|}{$\begin{array}{c}\text { Recovery period after physical } \\
\text { workload }\end{array}$} \\
\hline & & & & in & $3 \mathrm{~min}$ \\
\hline \multirow{4}{*}{$\begin{array}{l}\max , \\
\mathrm{mV}\end{array}$} & & $0.86 \pm 0.05$ & $0.86 \pm 0.25$ & .35 & 0.98 \\
\hline & cross-count & $0.99 \pm 0.12^{\#}$ & $1.07 \pm 0.41$ & $0.82 \pm 0.38$ & 0.88 \\
\hline & Swimmers & $0.76 \pm 0.17^{\circ}$ & $0.94 \pm 0.10$ & $0.93 \pm 0.10$ & $0.74 \pm 0.09$ \\
\hline & we & $0.91 \pm 0.16$ & $0.87 \pm 0.31$ & $0.87 \pm 0.40$ & 0.30 \\
\hline \multirow{4}{*}{$\min }$, & un & 0.34 & $0.40 \pm 0.09$ & & $0.42 \pm 0.03^{*}$ \\
\hline & cross-country skiers & $0.35 \pm 0.08$ & $0.50 \pm 0.09^{*}$ & $0.53 \pm 0.16^{*}$ & $0.30 \pm 0.06$ \\
\hline & swimmers & $0.36 \pm 12$ & $0.39 \pm 0.10$ & $0.41 \pm 0.10$ & $0.33 \pm 0.10$ \\
\hline & weightlif & $0.33 \pm 0.11$ & $0.44 \pm 0.24$ & $0.39 \pm 0.13$ & $0.32 \pm 0.14$ \\
\hline \multirow{4}{*}{$\max$} & untrained people & $220 \pm 16$ & $136 \pm 14^{*}$ & $149 \pm 18^{*}$ & $161 \pm 20^{*}$ \\
\hline & cross-country skiers & $256 \pm 54$ & $166 \pm 5^{* \#}$ & $197 \pm 17^{\#}$ & $228 \pm 37^{\# \#}$ \\
\hline & swimmers & $250 \pm 32$ & $150 \pm 14^{* \circ}$ & $173 \pm 26^{*}$ & $197 \pm 35^{*}$ \\
\hline & weightlifters & $225 \pm 37$ & $156 \pm 27^{*}$ & $160 \pm 44^{*}$ & $175 \pm 57$ \\
\hline \multirow{4}{*}{$\begin{array}{l}\mathrm{t}_{\min } \\
\mathrm{ms}\end{array}$} & untrained people & $234 \pm 14$ & $141 \pm 14^{*}$ & $154 \pm 19^{*}$ & $156 \pm 18^{*}$ \\
\hline & cross-cou & $272 \pm 39^{\#}$ & $165 \pm 7 * \#$ & $198 \pm 15^{* \#}$ & $199 \pm 47^{*}$ \\
\hline & swimmers & $263 \pm 20^{\wedge}$ & $147 \pm 16^{*}$ & $160 \pm 20^{*}$ & $207 \pm 33^{* \wedge}$ \\
\hline & weightlifters & $226 \pm 38$ & $156 \pm 17^{*}$ & $175 \pm 22^{*}$ & $190 \pm 39$ \\
\hline
\end{tabular}

$P<0.05$ in comparison to: ${ }^{*}-$ baseline; ${ }^{*}$ - between cross-country skiers and untrained people; - between swimmers and cross-country skiers; $\wedge$ - between swimmers and untrained people

Thus, the study of the heart's electric field in athletes of the same sex, age and sport qualification, but different sport disciplines, showed that the reaction of the heart to physical activity is reflected in different changes of the amplitude-temporal characteristics of the extremes on the body's surface in athletes with eccentric and concentric myocardial remodeling.

\section{Sources of Funding}

The reported study was supported by KSC UB RAS according to Research Project AAAA-A18-118012390260-9 and by UB RAS according to the Complex Program AAAA-A18-118012390269-2.

\section{Competing Interests}

The authors declare that they have no competing interests.

\section{References}

1. Mitchell JH, Haskell W, Snell P, Van Camp SP. Task Force 8: classification of sports. J Am Coll Cardiol. 2005;45(8):1364-7.

2. Scharhag J, Löllgen H, Kindermann W. Competitive sports and the heart: benefit or risk? Dtsch Arztebl Int. 2013;110(12):14-23; quiz 24; e1-2. doi: 10.3238/arztebl.2013.0014.

3. Weeks K, McMullen J. The Athlete's heart vs. the failing heart: can signaling explain the two distinct outcomes? Physiology. 2011;26(2):97-105. doi: 10.1152/physiol.00043.2010.

4. Weiner RB, Baggish AL. Exercise-induced cardiac remodeling. Prog Cardiovasc Dis. 2012;54(5):380-6. doi: 10.1016/j.pcad.2012.01.006.

5. Gussak I, Antzelevitch C, Wilde AAM, Powell BD, Ackerman MJ, Shen WK. (Eds.) Electrical diseases of the heart. 2nd Edition. Springer-Verlag London Ltd; 2013.

6. Drezner JA, Ackerman MJ, Anderson J, Ashley E, Asplund $\mathrm{CA}$, Baggish AL, et al. Electrocardiographic interpretation in athletes: the 'Seattle criteria'. Br J Sports Med. 2013 Feb;47(3):122-4. doi: 10.1136/bjsports-2012-092067.

7. Sharma S, Drezner JA, Baggish A, Papadakis M, Wilson MG, Prutkin JM, et al. International Recommendations for Electrocardiographic Interpretation in Athletes.J Am Coll Cardiol. 2017;69(8):1057-1075. doi: 10.1016/j.jacc.2017.01.015.

8. Fagard R. Athlete's heart. Heart. 2003;89(12):1455-61.

9. Roshchevskaya IM. Cardioelectric field of warm-blooded animals and humans. St. Petersburg: Nauka; 2008. [In Russian].

10. De Ambroggi L, Corlan AD. Body Surface Potential Mapping Comprehensive Electrocardiology. Springer-Verlag London Ltd. 2011;3:1375-1415.

11. Lang RM, Bierig M, Devereux RB, FlachskampfFA, Foster E, Pellikka PA, et al.; American Society of Echocardiography's Nomenclature and Standards Committee; Task Force on Chamber Quantification; American College of Cardiology Echocardiography Committee; American Heart Association; European Association of Echocardiography, European Society of Cardiology. Recommendations for chamber quantification. Eur J Echocardiogr. 2006;7(2):79-108.

12. Regecova V, Kellerova E, Aidu EA. Characteristics of the cardiac electric field in young subjects related to blood pressure and obesity. Electrocardiology. Wroclow. JAKS Publishing Company; 2009.

13. Martirosov EG, Nikolaev DV, Rudnev SG. Technologies and methods for determining the composition of the human body. M.:Nauka; 2006. [In Russian].

14. Strel'nikova SV, Panteleeva NI, Roshchevskaia IM. [Spatiotemporal characteristics, of the heart electrical field at the period of ventricular depolarization in athletes training endurance and strength]. Fiziol Cheloveka. 201;40(5):87-92.[Article in Russian].

15. Smolensky AV, Mikhailova AV, Tatarinova AYu. Arterial hypertension and heart remodeling in athletes. International Journal of Heart and Vascular Diseases. 2017;5(14):36-45.

16. Uskova OV, Sobolev KO, Storozhakov GI. [Hypertrophy of the left ventricle of the heart: diagnosis, consequences and prognosis]. Lechebnoe Delo. 2012;2:4-8 [Article in Russian]. 17. Suslonova OV, Smirnova SL, Roshchevskaya IM. [Cardioelectric field on the body surface of 12-month-old hypertensive Nisag rats during the initial and terminal ventricular activity]. Mezhdunarodniy zhurnal prikladnih i fundamental'nih issledovaniy. 2016;8:732-35. [Article in Russian]. 